\title{
Exploring Undergraduate Students' Usage Pattern of Mobile Apps for Education
}

\begin{abstract}
In recent years, with the general adoption of smartphones with computing power comparable to desktop computers, mobile applications (apps) have experienced a surge in popularity. However, there are a few studies conducted about their educational use, especially in Southeast Asia. To fill up this research gap, this study aims to provide a current overview of mobile apps usage in higher education. Besides exploring the actual use of apps, Technology Acceptance Model was applied to examine (1) undergraduate students' perceptions, which involve perceived usefulness (PU) and perceived ease of use (PEOU), towards adopting mobile apps for educational purposes, and (2) their overall attitude (OA) toward such adoption. Both quantitative and qualitative methods are used to collect data from 150 undergraduate students in Business, Education, and Engineering in Hong Kong. The results show undergraduate students use mobile apps frequently to engage in learning activities related to their academic studies, with a particularly focus on communication and collaborative working, accessing academic resources, and checking dictionary. However, the discrepancies in using apps for academic purposes are not significant between the three faculties. Meanwhile, PU has a more positive impact on OA compared with the impact of PEOU on OA. The investigation helps tertiary institutions, library service providers, and educators develop and assess the strategic planning for education collaborating with mobile apps. This paper could also give app developers some hints on the app design based on the actual usage and students’ information needs.
\end{abstract}

\section{Keywords:}

mobile applications (apps), Technology Acceptance Model (TAM), Hong Kong, qualitative study, quantitative study. 


\section{Introduction}

Among more than 75 billion apps downloaded from the Apple App Store as for Summer 2014, education was the third-most popular category in the share of active mobile applications (apps) (Statista, 2015). With the rising popularity in using apps, mobile technologies in fact have high potentials for educational use, especially in university studies. Plus, the mobile computing environment has radical changes in recent years, including the increase of computing power of smartphones, their diffusion, the improvement of the mobile bandwidth availability and various costs. The availability of apps for educational use, the reduction of cost of using mobile networks to online, and the increase of mobile bandwidth capacity are becoming the enablers for the era of mobile learning revolution. Prior research (Nevin, 2009) also shows that the use of mobile apps in learning and teaching can help to engaging students in the lecture, and apps definitely have significant impacts on improvement of learning by students. However, there have been inadequate studies about the use and perceived needs of mobile apps for learning purposes, especially in the Asia Pacific region.

This study aims to examine the current usage of mobile apps for learning purposes amongst undergraduate students in Hong Kong. It also attempts to investigate the relationship between the students’ perceived usefulness (PU), perceived ease of use (PEOU), and overall attitude (OA) towards the use of mobile apps in education, together with their learning behaviors of using mobile apps, with reference to the Technology Acceptance Model (TAM) (Davis, 1993). Quantitative and qualitative research methods were used for analysis of the above research questions. This research could also identify students’ learning needs of using mobile apps that might contribute to the usefulness of mobile apps' functions for learning, and thus provide implications about the development of effective pedagogy planning that involves mobile technologies for tertiary institutions, library service providers, and educators. 
This paper is developed as follows. First, we review the literature on the history of mobile learning, its application in higher education, and adoption in mobile apps, and develop our research questions. Next, we present our methodology and report our data analysis, which includes an online survey and a series of face-to-face interviews for collecting responses from undergraduate students in the use mobile apps for academic use. We will end our paper with a discussion of our findings, as well as the theoretical contributions, practical implications, and limitation of this study.

\section{Literature review}

\section{Mobile technologies and mobile learning}

Nowadays, mobile technologies have been repositioned which is being more than just a communication tool. Supported by the advancement in technology such as wireless network development and the

increase of capability in devices, researchers recognize the fact that mobile technology is rapidly being used as a learning tool (Hall, 2008; Kim et al., 2013). Portable devices like smartphones, tablets, and ebook readers appear as powerful instruments for students' learning. Thus, the concept of "mobile learning” (m-learning) has been established to link up "mobile” and "learning," which seems to be two totally separated ideas in the past.

M-learning is suggested as an improvement of education environment in e-learning as well as a new and independent part of e-learning (Cho, 2007; Keegan, 2002; Laouris and Eteokleous, 2005). However, it is hard to trace when the concept of "mobile learning” exactly appears. At the initial stage, there were many words and terms illustrating the same phenomenon. The term "m-learning" is suggested to be highly recognized in 2005 when Laouris and Eteokleous (2005) reported the sharply increased Google search results in only six months' time. Moreover, the definitions of the term are varied. Researchers and practitioners have endeavored to demonstrate their knowledge of m-learning in various aspects: pedagogy, technological devices, context, and social interactions (Crompton, 2013). 
Recently, a more general definition is introduced to cover all these views for m-learning by Crompton (2013), who suggests that m-learning is "learning across multiple contexts, through social and content interactions, using personal electronic devices” (p. 4).

Traxler (2007, p. 14) clearly stated m-learning is a kind of stimulation in "multidisciplinary and interdisciplinary thinking" in education, which is not just about "mobile" or about "learning". Due to the growing popularity of m-learning, many scholars have studied its positive characteristics in terms of learning (Aharony, 2014; Cochrane and Bateman, 2010; Dyson et al., 2009; Park et al. 2012; Viberg and Grönlund, 2013). Meanwhile, Cochrane and Bateman (2010), and Dyson et al. (2009) have stressed on the benefits of m-learning on portability, flexibility, and context of mobile technologies facilitate a broader sense of learning, while others emphasize on its characteristics on breaking the restrictions of physical time and space and leads learning issues situate in a ubiquitous manner (O’Donoghue, 2010; Traxler, 2007).

On the other hand, several limitations of m-learning have also been discussed in the literature, including technical, psychological and pedagogical ones (Viberg and Grönlund, 2013). Technical limitations mainly refer to hardware deficiency such as small screen size, inadequate memory, lowresolution (El-Hussein and Cronje, 2010; Haag, 2011; Viberg and Grönlund, 2013), as well as competitbility (Stockwell, 2010). These limitations are gradually overcome as current smartphones and tablets have computing power comparable to desktop PCs and have larger high-definitions screens. Therefore, the situation worth re-examination.

Psychological limitations relates to the low possibility or longer time required on changing learning habits from face-to-face learning to m-learning (Park, 2011). However, as smartphones have currently become such a popular daily tool and activity for the younger generation, it is possible that our younger generations would be ready to adopt to the change this learning habits. Finally, the pedagogical 
limitations include the need to provide additional assistance to faculty and students who have weaker technological skills, the ease of cheating, and the possibility of diminishing communication skills (Corbeil and Valdes-Corbeil, 2007). Nevertheless, because of the rapid advancement in mobile device capability, researchers concur in the wider choices of learning resources, access to fulfill the needs of individual and, in particular, collaborative learning (Naismith et al., 2004; Norris and Soloway, 2011).

\section{Mobile-applications adopt in higher education}

There have been significant efforts in the studying of m-learning in higher education context due to the general requirements of collaborative and student-centered learning. Although relevant studies can be found in multiple disciplines, a majority of them investigated three main areas: distance learning (Fuegen, 2012; Rosli et al., 2010; Traxler, 2010), bilingual or language/linguistic studies (Cavus and Ibrahim, 2009; Che et al., 2009; Viberg and Grönlund, 2013), and library and information science (Aharony, 2014; Chang, 2013).

Researchers have distinguished the importance of students' nature and their differences from the predecessors. Students nowadays have been identified as "Digital Natives," who are highly influenced by contemporary technology changes (Prensky, 2001). This generation is typically equipped with proficient knowledge in using high tech devices and frequently surfing on wireless Internet to obtain necessary information. In order to cope with their learning needs, high mobility and informative Internet contents accessible from portable devices would be their favorite. Plus, to stimulate teamwork and reinforce real world skills, universities are experimenting with digital policies, which allow more interactions between students when working on projects and assessments (Johnson et al., 2014). It includes providing a pervasive Wi-Fi environment on campus, which is a crucial part in m-learning.

Recently, the research focus of m-learning has shifted from studying on m-learning's characteristics in general to studying on the development and use of mobile apps for higher education. A 
mobile app is "a software package that can be installed and executed in the mobile device" (Yan et al., 2013). Currently, mobile apps are considered as a key emerging technology in higher education (Johnson et al., 2014). It is believed that the trend of mobile apps for learning has been taken in progress for both educators and students. Vázquez-Cano (2014) views recent educational opportunities for integrating apps are "increasing more quickly than ever before.” Such high demand drives both the number and variety of apps to rises continuously. Apart from newly created apps, many popular applications and web services available on desktop computers are migrated into mobile versions, including Facebook, news websites, and educational apps.

Previous research on mobile apps in higher education mainly focuses on examining the usage rate of different categories of apps, in order to predict students' behavior in using them for learning. One of the significant findings from Bomhold (2013) discloses that a majority of university students (76\%) utilize smartphone apps for academic learning. In addition, other research compares apps usage in different groups of students (distinguished by their academic disciplines). For example, Kim et al. (2013) analyzed how students from different majors (education and engineering) used smartphone for learning through their regularly used apps in a Korean university. The findings conclude that those students who use smartphones heavily tend to put more time on the apps for learning, but they would install less learning apps on their phone when compared with others. Plus, other research explores the initiative of students to adopt apps for academic purpose. For example, Bomhold (2013) recognized that convenience of gathering information is important for current digital natives, and the reason is their expectation that information must be accessible "anytime, anywhere" instead of being lazy. 


\section{Gaps in mobile education research}

As discussed above, prior literature shows that while m-learning can be a useful tools for learning, it has several limitations. In particular, its psychological and pedagogical limitations are more difficult for overcome compared with its technical limitation. At the same time, mobile apps are also becoming important keys of success (or failure) in m-learning. However, scant research has been conducted in examining the role of mobile apps designed solely for academic learning, as mobile apps are relatively new technology for academic purpose. As shown in a recent review on the trends on mobile learning study conducted by Wu et al. (2012), no research has been done on mobile apps up to 2010. Therefore, in this study, we would like conduct a more in-depth and thoughtful research in this topic in order to fill the gap of mobile apps in learning. In particular, we would like to know the perception of undergraduate students on m-learning apps by conducting mixed method research (Creswell, 2003; Tashakkori and Creswell, 2007).

\section{Research questions addressed in this study}

To fill up the research gaps, we carry out a study on the actual academic use of apps by students from three different faculties of a university in Hong Kong. We attempt to identify and address research questions concerning the factors to affect undergraduate students' decision-making on the use of mobile apps for learning. First, we are interested in understanding the use of mobile apps for academic learning by undergraduate students in general. This piece of information would be a useful start-up point for future research. We would look into this matter through collecting statistics related to the level of usage of mobile apps in learning (including how often they use such apps, what are the common apps they use, and other related issues). From that, we hope to probe into the first research question (RQ) of this research, i.e., 
RQ1: What is the phenomenon of using mobile apps for academic study by undergraduate students from Hong Kong?

The second issue that we would like to investigate in this study is the factors affecting the actual use of mobile apps for academic study by the undergraduate students. In other words, our RQ is:

RQ2: What are the factors affecting the actual use of mobile apps for academic study?

To investigate into RQ2, we decided to use the Technology Acceptance Model, TAM (Davis, 1989, 1993) as the theoretical framework, which has been widely spread in explaining and predicting system and technology use (Lee et al., 2003). In the educational field, TAM has been applied to outline students' attitude on the designed technology. By looking into students' perception on the ease of use (i.e., perceived ease of use, PEOU) and the usefulness (i.e., perceived usefulness, PU) on an educational technology, researchers can predict students' behaviors and acceptance level on its adoption (Cheon et al., 2012; Liu et al., 2010). For example, Park (2009) used the TAM to study students' acceptance in elearning, and Park et al. (2012) also illustrated both direct and indirect effects on university students' behavioral intention on using m-learning. Park et al. (2012) also concluded that students' adoption of mlearning is not only affected by the overall attitude (OA) towards the technology and their PU, but also affected by other factors such as the students' major, their subject norm and system accessibility. Plus, Lai et al. (2012) discovered the possible factors which would stimulate students' use of technology for learning using the TAM as the theoretical foundation.

To probe into our RQ2, we propose the following set of hypotheses based on the TAM:

H1a Students' perception on the ease of use (PEOU) of the mobile apps for academic learning is positively affecting their perceived usefulness (PU) on the apps.

H1b Students' perception on the ease of use (PEOU) of the mobile apps for academic learning is positively affecting their overall attitude (OA) on those apps. 
H1c Students' perception on the usefulness (PU) of the mobile apps for academic learning is positively affecting their overall attitude (OA) on those apps.

H1d Students' overall attitude (OA) towards the mobile apps is positively affecting the level of their actual usage (AU) of those apps.

Last but not least, we are also interested in whether students from different majors/faculties would have a different usage behavior. Prior research (Ho, 2014) reports that learners of different academic background would have different adoption behaviors in using e-learning technology. Therefore, we anticipate that a similar observation will be found in this study, i.e., subjects from the three different faculties would have a different usage behavior in mobile apps for academic study and their adoption on the mobile apps. Thus, we have the following set of hypotheses:

H2a: Students from different majors would have a different level of usage of mobile apps for academic study.

H2b: The impact of the relationships developed based on the TAM would be affected by the students' major.

\section{Methodology and data collection}

In this study, we used mixed methods research to triangulate the research questions and hypotheses that we would like to address. For the quantitative method, a quantitative online questionnaire was designed for exploring the general perspectives on adopting mobile apps for learning from undergraduates from three faculties in a university, i.e., (i) the Faculty of Business and Economics (a.k.a. business major), (ii) the Faculty of Education (a.k.a. education major), and (iii) the Faculty of Engineering (a.k.a. engineering major). The survey instrument was a 40-question survey, which were adapted from various prior studies, and requires about 15 minutes to complete. It is divided into three parts for the purpose of collecting 1) demographic information, 2) students' general behaviors on using mobile apps, and 3) their intention 
and usage on adopting apps for academic learning. For the data collection of students' general behaviors on using mobile apps, we asked questions about their general usage patterns (such as number of apps used and downloaded), as well as their usage behavior on education apps. We used the appropriate types of statistical tests ( $\chi^{2}$-test and ANOVA) to conduct the data analysis. For the study on the intention and usage on adopting apps for academic learning based on the TAM, we used structural equation model to analysis our data. A pilot test was conducted on 6 respondents, and confirmed that no amendment was needed for the questionnaire. A total of 150 subjects, 50 each from each of the faculty concerned, had participated in the survey voluntarily.

For the qualitative method, we conducted a series of one-to-one telephone interview to investigate the reasons behind of using apps for learning. Ten subjects were willing to participate in the telephone interviews and eventually, we interviewed six of them, two from each faculty. The interviews were conducted in Cantonese and Mandarin, and the interview notes were transcribed back into English. To minimize any difficulties caused by language barriers and ensure that all the participants could share their opinions fluently, the selection of interview languages were based on the subjects' personal preferences. Generally, each interview took no more than 15 minutes.

\section{Data analysis}

\section{Demographic background and general mobile apps usage behavior}

Demographic background of our subjects as well as the number of mobile apps installed and purchased, with the $p$-values of $\chi^{2}$ test on each category of demographics, is presented in Table 1. First, we observed a significant gender difference $(p<0.01)$ at the faculty level, while the gender difference is not significant in the overall level. In particular, there are more than half of engineering students were male whereas more than $70 \%$ of subjects from the Faculty of Education were female, which is in line with the gender distribution at faculty level. Plus, we also observed a significant difference on the level of study 
among subjects $(p<0.01)$, as most of the subjects from the Faculty of Business and Economics were freshmen and all subjects from the Faculty of Education were from the upper division.

Table 1. Demographic background of subjects $(n=150)$.

\begin{tabular}{|c|c|c|c|c|c|}
\hline & Business & Education & Engineering & Overall & $p$-value \\
\hline \multicolumn{6}{|l|}{ Gender } \\
\hline Male & $28(56.0 \%)$ & $15(30.0 \%)^{*}$ & $34(68.0 \%)$ & 77 (51.3\%) & $<0.01$ \\
\hline Female & $22(44.0 \%)$ & $35(70.0 \%)^{*}$ & $16(32.0 \%)$ & $73(48.7 \%)$ & \\
\hline Total & 50 & 50 & 50 & 150 & \\
\hline \multicolumn{6}{|l|}{ Levels of study } \\
\hline Year 1 & $40(80.0 \%)$ & $0(0.0 \%)$ & $21(42.0 \%)$ & $61(40.7 \%)$ & $<0.01$ \\
\hline Year 2 & $6(12.0 \%)$ & $0(0.0 \%)$ & $10(20.0 \%)$ & $16(10.7 \%)$ & \\
\hline Year 3 & $4(8.0 \%)$ & $22(44.0 \%)^{*}$ & $14(28.0 \%)$ & $40(26.7 \%)$ & \\
\hline Year 4 or above & $0(0.0 \%)$ & $28(56.0 \%) *$ & $5(10.0 \%)$ & $33(22.0 \%)$ & \\
\hline Total & 50 & 50 & 50 & 150 & \\
\hline \multicolumn{6}{|l|}{ Number of total apps } \\
\hline$<20$ & $12(24.0 \%)$ & $16(32.0 \%)$ & $20(40.0 \%)$ & 48 (32.0\%) & 0.527 \\
\hline $20-50$ & $28(56.0 \%)$ & $27(54.0 \%)$ & 22 (44.0\%) & 77 (51.3\%) & \\
\hline $51-80$ & $8(16.0 \%)$ & $6(12.0 \%)$ & $7(14.0 \%)$ & $21(14.0 \%)$ & \\
\hline $81-110$ & $2(4.0 \%)$ & $0(0 \%)$ & $1(2.0 \%)$ & $3(2.0 \%)$ & \\
\hline$>110$ & $0(0 \%)$ & $1(2.0 \%)$ & $0(0 \%)$ & $1(0.7 \%)$ & \\
\hline \multicolumn{6}{|l|}{ Purchase apps } \\
\hline$\overline{0}$ & $37(74.0 \%)$ & $34(68.0 \%)$ & $29(58.0 \%)$ & $100(66.7 \%)$ & \\
\hline $1-3$ & $1(2.0 \%)$ & $1(2.0 \%)$ & $0(0 \%)$ & $2(1.3 \%)$ & 0.411 \\
\hline $4-6$ & 0 & 0 & 0 & $0(0 \%)$ & \\
\hline $7-10$ & $11(22.0 \%)$ & $15(30.0 \%)$ & 19 (38.0\%) & 45 (30.0\%) & \\
\hline$>10$ & $1(2.0 \%)$ & $0(0 \%)$ & $2(4.0 \%)$ & $3(2.0 \%)$ & \\
\hline
\end{tabular}

Concerning the number of mobile apps installed and mobile apps purchasing experience, our subjects did not have any statistically significant differences in their behavior, i.e., with $\mathrm{p}>0.05$ in a $\chi^{2}$ test. In general, over half of the subjects possessed 20-50 apps while less than one-fifth of respondents possessed more than 50 apps. Besides, one-third of the subjects had experience in purchasing apps, and majority of them had purchased 7-10 apps in total. Our results suggest that students were frequently use mobile apps, and some of them were willing to pay money for subscribing apps in order to satisfy their needs. 
We also capture the mobile phone procession rate for our subjects. It is not surprising to note that the mobile phone possession rate among our subjects were $100 \%$, which echoes the findings of Dahlstrom (2012) and Bomhold (2013). From Table 2, we found that our subjects often use apps to fulfill their everyday needs (i.e., with an average of 3.97 on a 5-point Likert scale). Education majors seemed to spend less time on using apps than their counterparts in business or engineering majors, but the difference is not statistically significant ( $p>0.05$ based on ANOVA).

Table 2. Usage frequency of mobile apps.

$\begin{array}{lll}\text { Business Education Engineering } & \begin{array}{c}\text { Weighted } \\ \text { Average }\end{array}\end{array}$

\begin{tabular}{lllll}
\hline $\begin{array}{l}\text { Frequency of usage for mobile } \\
\text { applications }\end{array}$ & 4.00 & 3.88 & 4.02 & 3.97 \\
\hline
\end{tabular}

Note: Scale: 1 = Never, 5 = Always.

\section{Adoption of mobile apps for academic study}

We observed that the usage rate of mobile apps for learning was generally high among our subjects (see Table 3). Only a minority of students (23 out of 150, or 15.3\%) indicated that they did not use apps for their academic studies. We are of the view that most students like to use apps for their academic studies because of the convenience provided by the portable devices. Plus, there is a statistically significant difference $(p<0.05)$ on the proportion of subjects using mobile apps for their academic studies across their majors. This result support our H2a.

Table 3. Using mobile apps for learning.

\begin{tabular}{lccccc}
\hline & Business & Education & Engineering & Overall & $p$-value \\
\hline Use apps for learning & & & & & \\
\hline Yes & $48^{*}$ & 39 & 40 & 127 & 0.02 \\
No & $2^{*}$ & 11 & 10 & 23 & \\
\hline
\end{tabular}

Note: ${ }^{*}$ Value significantly different from the other faculties based on $\chi^{2}$ test.

We also checked the responses of those subjects who did not adopt mobile apps to assist their academic studies to find out their barriers of adopting mobile apps usage for learning purpose. We noted 
that the major factors included limited screen size of mobile, compatibility and applicability of apps, which were technical in nature. This result echoes the findings reported by the literature (El-Hussein \& Cronje, 2010; Haag, 2011; Stockwell, 2010; Viberg \& Grönlund, 2013).

Opinions from the face-to-face interviews also mentioned these as the disadvantage of learning using mobile apps. For example, our subject D (an Education senior student) says,

“.... I found that some apps, ...... , on my mobile sometimes have errors, thus the apps cannot work properly. I would prefer using other devices like my computer under the circumstances. ....., there is always compatibility problem among the apps and the mobile system.”

Plus, our subject F (an engineering freshman) also says, “.... some apps’ content designed for learning computer language is insufficient and even incomplete. So it is much better use laptop or computer. ......, the capability might not good enough ..... as the app sometimes out of control or have no reactions.”

We also looked into the number of apps that students used or purchased for academic learning and noted that there was no significant differences between the usage and purchase patterns across majors $(p>0.05)$ (see Table 4).

Table 4. Number of mobile learning apps used and purchased.

\begin{tabular}{|c|c|c|c|c|c|}
\hline & Business & Education & Engineering & Overall & $p$-value \\
\hline \multicolumn{6}{|c|}{ Number of apps for learning } \\
\hline 0 & $2(4.0 \%)$ & $11(22.0 \%)$ & $10(20 \%)$ & $23(15.3 \%)$ & 0.152 \\
\hline 1 to 5 & $29(58.0 \%)$ & $23(46.0 \%)$ & 27 (54\%) & 79 (52.7\%) & \\
\hline 6 to 10 & $15(30.0 \%)$ & $10(20.0 \%)$ & $11(22 \%)$ & $36(24.0 \%)$ & \\
\hline 11 to 15 & $2(4.0 \%)$ & $5(10.0 \%)$ & $1(2 \%)$ & $8(5.3 \%)$ & \\
\hline More than 15 & $2(4.0 \%)$ & $1(2.0 \%)$ & $1(2 \%)$ & $4(2.7 \%)$ & \\
\hline Total & 50 & 50 & 50 & 150 & \\
\hline \multicolumn{6}{|c|}{ Purchase apps for learning } \\
\hline Yes & 3 & 2 & 7 & 12 & 0.108 \\
\hline No & 45 & 37 & 33 & 115 & \\
\hline Total & 48 & 39 & 40 & 127 & \\
\hline
\end{tabular}

Notes: (1) All values are not significantly different from the other faculties based on $\chi^{2}$ test. 
(2) The purchase apps for learning only include respondents who had used apps for learning

We also note that only a small proportion of our subjects (12 out of 127 , or $9.45 \%$ ) have purchased apps for learning. It may imply that our subjects’ intention to purchase mobile apps usage for learning was indeed independent of the usage rate of learning via mobile apps. When we further analyzing the responses from our subjects, we noted that there were three reasons for them not to purchase mobile apps for learning purposes, i.e., financial, quality, and necessity reasons. For financial concern, many respondents claimed that they did not have money to buy apps. Further, they deemed that it was worthless to purchase apps for learning due to the poor connection between the price and the quality of an app currently. In other words, they were of the view that the mobile apps were over-priced or not value-for-money, which is the joint-impact of financial and quality reasons. The situation is now becoming more complicated when there are more and more of free apps with similar functions which may be further encouraging students for using the free mobile apps than using the paid apps

We also explored on the type of mobile apps used by undergraduate students for supporting their academic study. We noted that the top three mobile apps they used for academic study were WhatsApp, dictionary apps, and Google Drive (see Table 5), with a slight discrepancy between each faculty.

Table 5. List of top three most frequently used mobile apps for learning.

\begin{tabular}{lcccc}
\hline & Business & Education & Engineering & Overall \\
\hline $\begin{array}{l}\text { The most frequently used } \\
\text { apps }\end{array}$ & Dictionary* & Whatsapp & Dictionary* & Whatsapp \\
& Whatsapp & Google Drive & Whatsapp & Dictionary* \\
G-mail & Dictionary* & G-mail & Google Drive \\
\hline Unique apps & Bloomberg & \multicolumn{3}{c}{ AutoCAD } \\
& & \multicolumn{3}{c}{ WolframAlpha } \\
\hline
\end{tabular}

We also report our findings on the usage frequency of different kinds of mobile apps for academic usage (see Table 6). The most frequently used types of apps for learning was Web search i.e., with an average of 4.32 on a 5-point Likert scale. It indicates that respondents weight information searching as the most significant function of using apps for learning, which is consistent with the 
findings observed by Roschelle (2003) that a key pedagogical activity in mobile learning is the ability of Web search and information retrieval on mobile devices. The results confirm that the overall information needs of our subjects were fulfilled by using search engines, which can provide sufficient data and information for their academic studies.

Table 6 Mobile apps usage for learning.

\begin{tabular}{lcccc}
\hline Frequency of using apps (in category) & Business & Education & Engineering & $\begin{array}{c}\text { Weighted } \\
\text { Average }\end{array}$ \\
\hline Mass media (e.g., TV, Radio, Newspaper) & 3.06 & 2.67 & 3.08 & 2.93 \\
Dictation and translation & 4.13 & 3.79 & 3.98 & 3.96 \\
Social networking & 3.73 & 3.72 & 3.55 & 3.67 \\
Browser & 4.44 & 4.33 & 4.18 & 4.32 \\
E-mail / texting & 4.25 & 4.38 & 4.00 & 4.21 \\
Map and navigation & 2.96 & 2.85 & 2.80 & 2.87 \\
Document viewer (e.g., PDF reader) & 4.25 & 4.15 & 3.95 & 4.12 \\
Notes & 3.60 & 3.10 & 3.48 & 3.39 \\
Schedule / calendar & 3.73 & 3.31 & 3.25 & 3.43 \\
Video (e.g. YouTube) & 3.15 & 3.03 & 2.95 & 3.04 \\
School apps & 2.38 & 2.28 & 2.30 & 2.32 \\
Recorder & 2.94 & 2.54 & 2.20 & 2.56 \\
Calculator & 3.54 & 2.95 & 2.98 & 3.18 \\
Others & 1.54 & 2.95 & 2.98 & 3.16 \\
\hline Not Scal & & & &
\end{tabular}

Note: Scale: 1 = Never, 5 = Always.

E-mail and texting (weighted average $=4.21$ ) is another common usage as relevant mail and news for administrating their academic studies as well as communications for academic discussions are important for our subjects' academic life. Further, the feedbacks that we conducted through the six interviewees also stressed the significance of this category of apps for learning.

We further explore the use of mobile apps by our subjects based on the usage categories, i.e., (i) communications and interaction, (ii) accessing academic materials, (iii) information organization and sharing, (iv) self-learning, (v) information searching, and (vi) course-based learning. The result is presented at Table 7. Instant messaging and e-mails were reported as top two most frequently apps usage for engaging in learning activities, with an average score of 4.36 and 4.22 respectively. This result is 
similar to the responses collected for investigating the most frequently used category apps for learning. Our subjects may prefer to spend more time on communication and interaction with others because of the convenience of texting on current smartphones with the support of advanced multi-lingual input methods. It also reflects that the main purpose of our subjects using apps for academic purposes was to organize and share information with their peers for group projects. This finding also echoes the idea of emphasizing learning with peers is collaboration (Kearney, Schuck, Burden, \& Aubusson, 2012), as the networking of apps offers "shared, socially interactive environments" that enables a high level enjoyment of collaboration with peers, teachers, and even professionals. The same opinion has been reflected by our interviewees. For example, our subject A, who was a freshman in Business major, says, "Personally, apps are very useful as they help me to capture the latest news and movement of various issues, like ..... classmates instant message".

Another comment from subject B, a sophomore in Business majors, also says,

"Besides, I also usually use communication apps, ...., for academic discussions of group projects and it is convenient to discuss with my group mates at any times".

In general, our interviewees reported the needs of an app design with stronger connection with fellow students so that interactions within the same program as well as cross-department collaborative works could be assisted, even though other learning platforms, such as Moodle, would be able to provide such services through the browser but did not have any mobile apps available.

We also noted that our subjects had a statistically higher usage of apps for communication and interaction (mean score $=4.22$ ) than the other 5 types of apps. Our subjects also had a lower level of usage of apps for self-learning (mean score $=3.17$ ) and course-based learning (mean score $=3.04)$. This result also indicates that our subjects were eager to use the mobile apps for communication and interaction, than using the apps for learning. 
Table 7 Mobile apps usage for learning activities engagement.

\begin{tabular}{|c|c|c|c|c|}
\hline Frequency of using apps (in learning activities) & Business & Education & Engineering & $\begin{array}{l}\text { Weighted } \\
\text { Average }\end{array}$ \\
\hline \multicolumn{5}{|l|}{ (A) Communication and interaction } \\
\hline Instant messaging (e.g., via WhatsApp, Line, etc.) & 4.52 & 4.54 & 4.03 & 4.36 \\
\hline Checking and/or sending e-mails & 4.38 & 4.41 & 3.88 & 4.22 \\
\hline $\begin{array}{l}\text { Social networking and knowledge sharing (e.g., } \\
\text { Facebook, Twitter) }\end{array}$ & 4.25 & 4.18 & 3.75 & 4.06 \\
\hline \multicolumn{5}{|l|}{ (B) Accessing academic materials } \\
\hline $\begin{array}{l}\text { Accessing Moodle to find lecturers notes, } \\
\text { reference readings, videos, etc. }\end{array}$ & 4.42 & 3.67 & 3.98 & 4.02 \\
\hline $\begin{array}{l}\text { Reading academic content (e.g., e-books, e- } \\
\text { journals) }\end{array}$ & 3.96 & 3.31 & 3.63 & 3.63 \\
\hline \multicolumn{5}{|l|}{ (C) Information organization and sharing } \\
\hline $\begin{array}{l}\text { Storing learning content online (e.g., uploading } \\
\text { on Dropbox, YouTube) }\end{array}$ & 3.67 & 3.31 & 3.53 & 3.50 \\
\hline $\begin{array}{l}\text { Online sharing and synchronized editing (e.g., } \\
\text { Google Drive) }\end{array}$ & 4.04 & 4.00 & 3.83 & 3.96 \\
\hline \multicolumn{5}{|l|}{ (D) Self-learning } \\
\hline Checking dictionary & 4.27 & 4.03 & 3.93 & 4.07 \\
\hline $\begin{array}{l}\text { Studying language via specific apps (e.g., Korean } \\
\text { Pocket Lingo) }\end{array}$ & 2.56 & 2.54 & 2.38 & 2.49 \\
\hline $\begin{array}{l}\text { Listening to or watching videos related to } \\
\text { academic learning, e.g. lectures, podcast }\end{array}$ & 3.17 & 2.92 & 2.73 & 2.94 \\
\hline $\begin{array}{l}\text { Searching literatures via library’s electronic } \\
\text { databases }\end{array}$ & 3.15 & 3.21 & 3.08 & 3.14 \\
\hline
\end{tabular}

\begin{tabular}{|c|c|c|c|c|}
\hline \multicolumn{5}{|l|}{ (E) Information searching } \\
\hline \multicolumn{5}{|l|}{ Using the university's campus website (e.g., } \\
\hline University Portal) & 4.15 & 3.46 & 3.60 & 3.74 \\
\hline Reading other content (e.g., newspapers, blogs) & 3.71 & 3.44 & 3.30 & 3.49 \\
\hline \multicolumn{5}{|l|}{ (F) Course-based learning } \\
\hline \multicolumn{5}{|l|}{ Completing coursework or participating in } \\
\hline lectures (e.g., online discussion) & 3.58 & 2.90 & 3.20 & 3.23 \\
\hline Submitting assignment & 3.60 & 2.51 & 3.13 & 3.09 \\
\hline Notes taking & 3.63 & 2.95 & 2.83 & 3.14 \\
\hline Collecting data (e.g., HeartBeat Counter for & & & & \\
\hline empirical study) & 2.98 & 2.15 & 2.65 & 2.60 \\
\hline
\end{tabular}

\section{The technology acceptance model (TAM) analysis}

To gain a better understanding on how the undergraduate students developed their actual use of mobile apps, we conducted a partial least square (PLS) analysis using SmartPLS 2.0 M3 (Ringle et al., 2005), 
with a bootstrapping algorithm with 500 cases and 500 re-sampling for calculating the $t$-value of path coefficients and factor loadings. The factor loadings and composite reliability values are reported at Appendix A for our overall samples and the models developed for samples collected from each major. As all $t$-value of the factor loadings are significant with $p<0.01$ and the values of composite reliability are larger than 0.7 , we concluded that our instrument has achieved convergent liability.

To test for discriminant validity, we first check if all items of the instrument have a loading greater than 0.7 on their respective factors, and have a low loading on other factors (Nunnally, 1978). While we noted that the factor loading values for the overall dataset and the engineering major dataset fulfilled this requirement, the factor loading values for PU3 and AU2 for the business major dataset were lower than the requirement, and PEOU1 for education major and business major were slightly lower. Then, we check if the square of the average variance extracted (AVE) of each latent construct is greater than the correlation of the construct concerned with other constructs in the model (See Appendix B). Our results show that all the cases, except the correlation between OA and PU for Education majors, could fulfill that requirement. In brief, we would consider that the instrument was having sufficient level of discriminant validity as we had positive check result for the overall sample.

Concerning the PLS models, we noted that our models (see Table 8) had good explanatory power as they could explain 54 to $72 \%$ of the overall adoption attitude towards mobile apps, and around 11 to $24 \%$ of the actual use of mobile apps.

Table 8 PLS results.

\begin{tabular}{|c|c|c|c|c|c|c|c|c|}
\hline \multirow[b]{2}{*}{ Variables } & \multicolumn{2}{|c|}{ Overall } & \multicolumn{2}{|c|}{ Education } & \multicolumn{2}{|c|}{ Engineering } & \multicolumn{2}{|c|}{ Business } \\
\hline & Coeff. & $\mathrm{R}^{2}{ }_{\text {(adj.) }}$ & Coeff. & $\mathrm{R}_{\text {(adj) }}^{2}$ & Coeff. & $\mathrm{R}^{2}{ }_{\text {(adj.) }}$ & Coeff. & $\mathrm{R}_{(\text {adj.) }}^{2}$ \\
\hline $\begin{array}{l}\text { PU } \\
\text { PEOU } \rightarrow \text { PU } \\
\text { OA }\end{array}$ & $0.720^{* *}$ & 0.518 & $0.704^{* *}$ & 0.496 & $0.757^{* *}$ & 0.572 & $0.647^{* *}$ & 0.419 \\
\hline $\begin{array}{l}\mathrm{PEOU} \rightarrow \mathrm{OA} \\
\mathrm{PU} \rightarrow \mathrm{OA} \\
\text { AU }\end{array}$ & $\begin{array}{l}0.121^{*} \\
0.696^{* *}\end{array}$ & 0.620 & $\begin{array}{l}0.168^{* *} \\
0.719^{* *}\end{array}$ & 0.716 & $\begin{array}{c}-0.137 \\
0.868\end{array}$ & 0.592 & $\begin{array}{l}0.348^{* *} \\
0.459^{* *}\end{array}$ & 0.539 \\
\hline $\mathrm{OA} \rightarrow \mathrm{AU}$ & $0.405^{* *}$ & 0.164 & $0.490^{* *}$ & 0.240 & $0.335^{* *}$ & 0.112 & $0.381^{* *}$ & 0.145 \\
\hline
\end{tabular}


Note: ${ }^{* *} \mathrm{p}<0.01 ;{ }^{*} \mathrm{p}<0.05$

As shown in Table 118 we can find the empirical support of our H1a, H1b, H1c, and H1d for all cases except for H1b for Engineering majors. To investigate into our H2b, which suggest that the level of impacts of TAM constructs would depend on the student majors, we conducted a post hoc test to compare their level of impacts. The post hoc test results are presented at Table 9. The results of the post hoc test show that the path coefficients of different major are statistically different with each other. Hence, our H2b is supported.

Table 9 Post hoc results.

\begin{tabular}{|c|c|c|c|c|c|c|}
\hline \multirow[b]{2}{*}{ Variables } & \multicolumn{2}{|c|}{$\begin{array}{c}\text { Education vs. } \\
\text { Engineering }\end{array}$} & \multicolumn{2}{|c|}{$\begin{array}{l}\text { Education vs. } \\
\text { Business }\end{array}$} & \multicolumn{2}{|c|}{$\begin{array}{c}\text { Engineering vs. } \\
\text { Business }\end{array}$} \\
\hline & Education & Engineering & Education & Business & Engineering & Business \\
\hline $\mathrm{PEOU} \rightarrow \mathrm{PU}$ & & & & & & \\
\hline Path Coefficient & 0.7041 & 0.7566 & 0.7041 & 0.6472 & 0.7566 & 0.6472 \\
\hline Difference & \multirow{2}{*}{\multicolumn{2}{|c|}{-0.0525}} & \multirow{2}{*}{\multicolumn{2}{|c|}{0.0568}} & \multicolumn{2}{|c|}{$0.1093^{* *}$} \\
\hline $\mathrm{PEOU} \rightarrow \mathrm{OA}$ & & & & & & \\
\hline Path Coefficient & 0.1679 & -0.1373 & 0.1679 & 0.3481 & -0.1373 & 0.3481 \\
\hline Difference & \multicolumn{2}{|c|}{$0.3052^{* *}$} & \multicolumn{2}{|c|}{$-0.1803^{* *}$} & \multicolumn{2}{|c|}{$-0.4855^{* *}$} \\
\hline $\mathrm{PU} \rightarrow \mathrm{OA}$ & & & & & & \\
\hline Path Coefficient & 0.7193 & 0.8683 & 0.7193 & 0.4589 & 0.8683 & 0.4589 \\
\hline Difference & \multirow{2}{*}{\multicolumn{2}{|c|}{$-0.1490^{*}$}} & \multicolumn{2}{|c|}{$0.2604^{* *}$} & \multirow{2}{*}{\multicolumn{2}{|c|}{$0.4094^{* *}$}} \\
\hline $\mathrm{OA} \rightarrow \mathrm{AU}$ & & & & & & \\
\hline Path Coefficient & 0.4900 & 0.3351 & 0.4900 & 0.3808 & 0.3351 & 0.3808 \\
\hline Difference & \multicolumn{2}{|c|}{$0.1549^{*}$} & \multicolumn{2}{|c|}{0.1092} & \multicolumn{2}{|c|}{-0.0457} \\
\hline
\end{tabular}

\section{Discussion}

\section{Academic use of mobile apps and their adoption}

Several implications can be inferred for educators, library service providers, and app developers in designing and promoting the use of mobile apps for higher education. First, mobile technology involving mobile Internet, smartphones and tablets seems to be inherent in the life of the younger generation nowadays, with a penetration rate more than $100 \%$ (as some young people have more than one device on average). In particular, university students are quick adopters of such new technology changes. Thus, it 
is not surprising to note that a majority of students showed their willingness to use apps on academic learning. Meanwhile, the actual use of apps in academic purpose was also high. It can be foreseen that there would be a continuous increase in coming future. Besides, this study attempted to gain an overview on both all samples and students in individual faculty in using apps for learning. However, it found that the most frequently used apps and the most frequently used types of apps stated by students were matched with each other. Coincidentally, in regard to the function on apps, results collected from three faculties were nearly the same. The most popular functions were related to communication and interaction, which could be WhatsApp; cloud storage, like Google Drive, and different kinds of dictionaries. Although students from different faculties may adopt some unique apps that specifically related to the nature of their curriculum and needs, general indication shows that their behavior on using apps are highly affected by academic assessment requirements (such as group projects requiring much communications for collaboration). Similar findings in another research on m-learning (Park et al., 2012) also show that relevance for students' major played a significant role in attitude on apps and its perceived usefulness.

Then, by applying the TAM, the correlation between PEOU, PU, OA, and AU had been throughout illustrated. Our study confirmed the positive correlations between the constructs as suggested by prior literature. More importantly, a significant finding in this research is that PU is a more significant construct affecting OA, compared with PEOU. One possible explanation can be illustrated by motivation theory, which is intensively utilized in explaining students’ behavior in pedagogy aspect. Prior research (for example, Viberg and Grönlund (2013)) suggests that students’academic success to their motivation on study. Further, motivation can be categorized into two major categories, namely intrinsic and extrinsic ones (Lei, 2010). So, PU could be considered as extrinsic motivation, which refers to external force, such as the desire for good academic outcomes. University students could be 
extrinsically motivated to use apps as learning tools when they perceive that apps are beneficial for their academic performance.

In higher education, inquiry-based learning is being emphasized more and more nowadays. Students are therefore directed to participate in group work for the purpose of encouraging collaborative knowledge sharing and synthesis (Bell et al., 2010). Accordingly, the top three activities related to academic learning we found are communication and interaction, accessing academic materials, and information organization and sharing. Due to the fact that high education should be a journey with a focus of self-investigation and self-learning, students are required to actively participate in numerous projects. Hence, demands on such tools and related service would increase accordingly. However, apparently there is lack of all-round apps which can satisfy students' needs on a larger scale of collaboration. For example, our subject B of the face-to-face interview expressed his concern that learning platforms (such as Moodle and many others) have not yet provided apps clients. Another subjects also raised similar concerns on the developing of suitable academic apps for class-based communication. Moreover, norms on the demand for virtual collaborative environment among students as there are increasing mobile-based support, for instance, mobile catalog interface in libraries, room booking in campus, etc. This echoes some early research findings such as Cheong et al. (2012), who suggest the importance for developing a framework of mobile-app-based collaborative learning system. Lastly, we also discover that students from Hong Kong were unwilling to purchase apps for academic purposes, even though they did use apps for learning due to three reasons: financial, quality, and necessity concerns. Based on the comments obtained from our face-to-face interviews, we discover two possible reasons for this phenomenon. First, the existence of free apps in the market already matches the basic need for students in using such apps for academic purposes. As the result, they would not search for any extra resources, especially not considering any purchases. Second, although free apps 
would probably unable to provide the best support for students in their learning, students still refuse to make purchase on the apps as they may not locate any apps that really worthy on a price that they were willing to pay for.

Based on the findings of this study, we are also able to make the following suggestions to educators, library service providers and apps developers. With reference to students’ positive responses on using apps for learning, administrators should consider developing learning apps as a supportive tool for faculty members, administrators, and students. Moreover, they are suggested to work closely to observe the situations of the general usage in mobile apps. Further in-depth research may need to conduct on the design and implementation of campus apps. Then, individual colleges should be consulted on their different needs in terms of nature of subject, instead of just a centrally developed generic solution. At priority, instant communication and document sharing functions are necessary to be improved. Aside from apps development, administrators should also suggest pedagogical guidelines for teachers on using apps for students for sharing and communications. Not only the credibility of apps would be increase among students, confusion in using an unnecessary variety of apps can be controlled. Prior research (Lai et al., 2012) has suggested that admission from instructors is crucial "to facilitate the transition of technologies from living tools to learning tools.”

Concerning the lower intention on purchasing apps of students nowadays, mobile apps designers have to put more efforts on collecting and understanding students' needs and concerns, and improve the applicability of the use of mobile apps in teaching and learning (Lin et al., 2011). Alternate revenue models, such as advertisement based revenue or institution licensing should be considered. Plus, mobile app developers should keep up with the latest knowledge on pedagogical development in the area in order to trace upcoming movements. On the other hand, developers on creating collaborative systems on mobile apps may have a niche. Especially, a more complex design which can engage multiple parties 
with more advanced communication functions would be favorite for students and institutions. This can encourage students to engage with the apps for academic purpose and probably would be able to expand the market share of the apps.

\section{Limitations and future research}

The study was carried out from an exploratory aspect, thus the sample sizes and scale of study is limited. However, it did provide insights for educators and librarians on students' behaviors on using apps for academic learning, especially for these three main majors that commonly exists in higher education institutes: Business, Education, and Engineering. Concerning the qualitative study, it would be better to have both focus group and face-to-face interviews, instead of only have a small number of face-to-face interviews. The use of group interview would enrich our findings as it would allow a chance for simulative sharing during the group interviews.

There are also several interesting areas for future research in this topic. First, there can be a larger scale of research which includes students from other faculties, such as Science, Medicine, and the Arts. Next, faculty members' and administrators' opinions on the issue should also be studied. It is necessary to implement research on this as educators' views are also valuable for future development. Besides, several external factors like social influences and technological environment in universities can change students' behaviors on using apps. On the other hand, we are planning to study the use of mobile apps in various real-life applications such as tourism (Chiu \& Leung, 2005), workforce management (Chiu, Cheung, \& Leung, 2005), and under emergency situations (Ng \& Chiu, 2006). 


\section{Conclusion}

This study examined undergraduates’ behaviors in utilizing mobile apps for academic learning. It confirmed that young people nowadays are comprised of positive attitude towards using mobile apps in daily life as well as for learning. Furthermore, our investigation in students’ preferences on using apps showed a consistent pattern of using apps in communication and interaction aspects, searching and checking for learning and reference materials, and information sharing. In addition, the diversity on mobile apps adoption related to different majors might not easy be distinguished from one to another

though minor discrepancies still exist among faculties according to different subject needs. Plus, we also used the TAM to study the mobile apps adoption behavior of undergraduate students from Hong Kong and noted that TAM could be used to explain their adoption behavior, and the major driving force for adoption is their perception on the usefulness of the mobile apps.

To conclude, our study demonstrated students’ adoption of mobile apps in both a general perception and a major-based reviewing. It can provide valuable implication for scholar, educator, librarians and related parties in the issue of "learning apps" for higher education. 


\section{References}

Aharony N (2014) Library and information science students’ perceptions of m-learning. Journal of Librarianship and Information Science 46(1): 48-61.

Bell T, Urhahne D, Schanze S and Ploetzner R (2012) Collaborative inquiry learning: Models, tools, and challenges. International Journal of Science Education 32(3): 349-377.

Bomhold C R (2013) Educational use of smart phone technology: A survey of mobile phone application use by undergraduate university students. Program: Electronic Library and Information Systems 47(4): 424-436.

Cavus N and Ibrahim D (2009) m-Learning: An experiment in using SMS to support learning new English language words. British Journal of Educational Technology 40(1): 78-91.

Chang C-C (2013) Library mobile applications in university libraries. Library Hi Tech 31(3): 478-492.

Che P-C, Lin H-Y, Jang H-C, Lien Y-N and Tsai T-C (2009) A study of English mobile learning applications at National Chengchi University. International Journal of Distance Education Technologies 7(4): 38-60.

Cheon J, Lee S, Crooks SM, and Song J (2012) An investigation of mobile learning readiness in higher education based on the theory of planned behavior. Computers \& Education 59(3): 1054-1064.

Cheong C, Bruno V and Cheong F (2012) Designing a mobile-app-based collaborative learning system. Journal of Information Technology Education 11(1): 94-119.

Chiu DKW, and Leung, HF (2005, August). Towards ubiquitous tourist service coordination and integration: a multi-agent and semantic web approach. In Proceedings of the 7th international conference on Electronic commerce (pp. 574-581). ACM.

Chiu DKW, Cheung SC, \& Leung HF (2005, January). A multi-agent infrastructure for mobile workforce management in a service oriented enterprise. In Proceedings of the 38th Annual Hawaii International Conference on System Sciences (pp. 85c-85c). IEEE.

Cho SK (2007) Current status and future of MALL. Multimedia Assisted Language Learning 10(3): 197-211.

Cochrane T and Bateman R (2010) Smartphones give you wings: Pedagogical affordances of mobile Web 2.0. Australasian Journal of Educational Technology 26(1): 1-14.

Corbeil JR and Valdes-Corbeil ME (2007) Are you ready for mobile learning? Educause Quarterly 30(2): 51-58.

Creswell JW (2003) Research Design: Qualitative, Quantitative, and Mixed Methods Approaches, 2nd 
edn. Thousand Oaks, CA: Sage Publications.

Crompton H (2013) A historical overview of m-learning: Toward learner-centered education. In Berge ZL and Muilenburg LY (eds.) Handbook of Mobile Learning New York, NY: Routledge, pp. 314.

Dahlstrom E (2012) ECAR Study of Undergraduate Students and Information Technology, 2012, Louisville, CO: EDUCAUSE Center for Applied Research.

Davis FD (1989) Perceived usefulness, perceived ease of use, and user acceptance of information technology. MIS Quarterly 13(3): 319-340.

Davis FD (1993) User acceptance of information technology: System characteristics, user perceptions and behavioral impacts. International Journal of Man-Machine Studies 38(3): 475-487.

Dyson LE, Litchfield A, Lawrence E, Raban R and Leijdekkers P (2009) Advancing the m-learning research agenda for active, experiential learning: Four case studies. Australasian Journal of Educational Technology 25(2): 250-267.

El-Hussein MOM and Cronje JC (2010) Defining mobile learning in the higher education landscape. Journal of Educational Technology \& Society 13(3): 12-21.

Fuegen S (2012) The impact of mobile technologies on distance education. TechTrends 56(6): 49-53. Haag J (2011) From elearning to mlearning: The effectiveness of mobile course delivery. In:

Proceedings of the Interservice/Industry Training, Simulation \& Education Conference 2011 (I/ITSEC 2011).

Hall B (2008) Five trends in the LMS market. Chief Learning Officer 7(1): 16.

Ho KKW (2014) The role of learners' academic background on e-learning: An empirical study on the use of discussion form. International Journal of Systems and Service-Oriented Engineering 4(4): 51-64.

Johnson L, Adams Becker S, Estrada V and Freeman A (2014) NMC Horizon Report 2014 - Higher Education Edition. Austin, TX: The New Media Consortium.

Kearney M, Schuck S, Burden K and Aubusson P (2012) Viewing mobile learning from a pedagogical perspective. Research in Learning Technology 20(1): Paper \#14406.

Keegan D (2002) The future of learning: From eLearning to mLearning.

Kim J, Ilon L and Altmann J (2013) Adapting smartphones as learning technology in a Korean university. Journal of Integrated Design \& Process Science 17(1): 5-16.

Lai C, Wang Q and Lei J (2012). What factors predict undergraduate students' use of technology for 
learning? A case from Hong Kong. Computers \& Education 59(2): 569-579.

Laouris Y and Eteokleous N (2005) We need an educationally relevant definition of mobile learning. In: Proceedings of the 4th World Conference on Mobile Learning, pp. 290-294.

Lei SA (2010) Intrinsic and extrinsic motivation: Evaluating benefits and drawbacks from college instructors’ perspectives. Journal of Instructional Psychology 37(2): 153-160.

Lee Y, Kozar KA and Larsen KRT (2003) The technology acceptance model: past, present, and future. Communications of the Association for Information Systems 12(1): Article 50.

Lin M-FG, Fulford C and Nakayama N (2011).Educational mobile apps scavenger hunt: Challenges, possibilities, and beyond. In: Barton S, Hedberg J andSuzuki K. (eds.), Proceedings of Global Learn Asia Pacific 2011 Association for the Advancement of Computng in Education, pp. 190 199.

Liu Y, Li H and Carlsson C (2010) Factors driving the adoption of m-learning. An empirical study. Computers \& Education 55(3): 1211-1219.

Naismith L, Sharples M, Vavoula G and Lonsdale P (2004). Literature Review in Mobile Technologies and Learning. Bristol, UK: Futurelab.

Nevin R (2009) Supporting 21st century learning through Google apps. Teacher Librarian, 37(2): 3538.

Ng, C. W., \& Chiu, D. K. (2006, January). e-Government integration with web services and alerts: a case study on an emergency route advisory system in Hong Kong. In Proceedings of the 39th Annual Hawaii International Conference on System Sciences, (Vol. 4, pp. 70b-70b). IEEE.

Norris CA and Soloway E (2011) Learning and schooling in the age of mobilism. Educational Technology 51(6): 3-10.

Nunnally JC (1978) Psychometric Theory, 2nd edn. New York, NY: McGraw-Hill.

O’Donoghue J (2010) Technology-Supported Environments for Personalized Learning: Methods and Case Studies. Hershey, PA: IGI Global.

Park SY (2009) An analysis of the technology acceptance model in understanding university students' behavioral intention to use e-learning. Educational Technology \& Society 12(3): 150-162.

Park SY, Nam M-W. and Cha S-B (2012) University students' behavioral intention to use mobile learning: Evaluating the technology acceptance model. British Journal of Educational Technology 43(4): 592-605.

Park Y (2011) A pedagogical framework for mobile learning: Categorizing educational applications of 
mobile technologies into four types. The International Review of Research in Open and Distributed Learning 12(2): 78-102.

Prensky M (2001) Digital natives, digital immigrants part 1. On the Horizon 9(5): 1-6.

Ringle CM, Wende S and Will A (2005). SmartPLS 2.0 (beta). Retrieved from http://www.smartpls.de

Roschelle J (2003) Keynote paper: Unlocking the learning value of wireless mobile devices. Journal of Computer Assisted Learning 19(3): 260-272.

Rosli M, Ismail I, Idrus RM and Ziden AA (2010) Adoption of mobile learning among distance education students in Universiti Sains Malaysia. International Journal of Interactive Mobile Technologies 4(2): 24-28.

Statista (2015). Most popular Apple App Store categories in June 2015, by share of available apps. Available at http://www.statista.com/statistics/270291/popular-categories-in-the-app-store/ (Accessed July 2015).

Stockwell G (2010) Using mobile phones for vocabulary activities: Examining the effect of the platform. Language Learning \& Technology 14(2): 95-110.

Tashakkori A and Creswell JW (2007) The new era of mixed methods. Journal of Mixed Methods Research 1(1): 3-7.

Traxler J (2007) Defining, discussing and evaluating mobile learning: The moving finger writes and having writ. The International Review of Research in Open and Distributed Learning, 8(2): Article 2.

Traxler J (2010) Distance education and mobile learning: Catching up, taking stock. Distance Education 31(2): 129-138.

Vázquez-Cano E (2014) Mobile distance learning with smartphones and apps in higher education. Educational Sciences: Theory \& Practice 14(4): 1505-1520.

Viberg O and Grönlund Å (2013) Cross-cultural analysis of users' attitudes toward the use of mobile devices in second and foreign language learning in higher education: A case from Sweden and China. Computers \& Education 69: 169-180.

Wu W-H, Wu Y-CJ, Chen C-Y, Kao H-Y, Lin C-H and Huang SH (2012) Review of trends from mobile learning studies: A meta-analysis. Computers \& Education 59(2): 817-827.

Yan Z, Dong Y, Niemi V and Yu G (2013) Exploring trust of mobile applications based on user behaviors: An empirical study. Journal of Applied Social Psychology 43(3) 638-659. 
Appendix A. Factor loading.

\begin{tabular}{|c|c|c|c|c|c|c|c|c|c|c|c|c|c|c|c|c|c|c|c|c|}
\hline & \multicolumn{4}{|c|}{ PEOU } & \multicolumn{4}{|c|}{ PU } & \multicolumn{4}{|c|}{$\mathrm{OA}$} & \multicolumn{4}{|c|}{ AU } & \multicolumn{4}{|c|}{ C.R. } \\
\hline & Overall & Ed. & Eng. & Bus. & Overall & Ed. & Eng. & Bus. & Overall & Ed. & Eng. & Bus. & Overall & Ed. & Eng. & Bus. & Overall & Ed. & Eng. & Bus. \\
\hline PEOU1 & 0.74 & 0.67 & 0.80 & 0.68 & & & & & & & & & & & & & 0.84 & 0.81 & 0.85 & 0.84 \\
\hline PEOU2 & 0.79 & 0.75 & 0.81 & 0.81 & & & & & & & & & & & & & & & & \\
\hline PEOU3 & 0.86 & 0.87 & 0.83 & 0.90 & & & & & & & & & & & & & & & & \\
\hline PU1 & & & & & 0.83 & 0.83 & 0.82 & 0.84 & & & & & & & & & 0.87 & 0.86 & 0.89 & 0.82 \\
\hline PU2 & & & & & 0.79 & 0.71 & 0.86 & 0.79 & & & & & & & & & & & & \\
\hline PU3 & & & & & 0.71 & 0.70 & 0.78 & 0.44 & & & & & & & & & & & & \\
\hline PU4 & & & & & 0.85 & 0.87 & 0.82 & 0.83 & & & & & & & & & & & & \\
\hline OA1 & & & & & & & & & 0.87 & 0.87 & 0.89 & 0.76 & & & & & 0.92 & 0.90 & 0.94 & 0.89 \\
\hline OA2 & & & & & & & & & 0.89 & 0.86 & 0.93 & 0.86 & & & & & & & & \\
\hline OA3 & & & & & & & & & 0.82 & 0.78 & 0.87 & 0.81 & & & & & & & & \\
\hline OA4 & & & & & & & & & 0.87 & 0.85 & 0.88 & 0.86 & & & & & & & & \\
\hline AU1 & & & & & & & & & & & & & 0.91 & 0.90 & 0.91 & 0.97 & 0.89 & 0.91 & 0.92 & 0.77 \\
\hline AU2 & & & & & & & & & & & & & 0.88 & 0.93 & 0.93 & 0.58 & & & & \\
\hline
\end{tabular}

Ed. = Education; Eng. = Engineering; Bus. = Business, PEOU = Perceived Ease of Use; PU = Perceived Usefulness; OA = Overall Attitude ; AU = Actual Use; C.R. = Composite Reliability

\begin{tabular}{lccccccccc} 
Appendix B. & \multicolumn{1}{l}{ Correlation matrices. } \\
\hline Overall & PEOU & PU & OA & AU & Education & PEOU & PU & OA & AU \\
\hline PEOU & $\mathbf{0 . 7 9 8}$ & & & & PEOU & $\mathbf{0 . 7 6 6}$ & & & \\
PU & 0.718 & $\mathbf{0 . 7 9 5}$ & & & PU & 0.704 & $\mathbf{0 . 7 8 3}$ & \\
OA & 0.621 & 0.783 & $\mathbf{0 . 8 6 1}$ & & OA & 0.674 & 0.837 & $\mathbf{0 . 8 3 7}$ & \\
AU & 0.305 & 0.435 & 0.405 & $\mathbf{0 . 8 9 9}$ & AU & 0.375 & 0.490 & 0.490 & $\mathbf{0 . 9 1 6}$ \\
\hline Engineering & PEOU & PU & OA & AU & Business & PEOU & PU & OA & AU \\
\hline PEOU & $\mathbf{0 . 8 1 0}$ & & & & PEOU & $\mathbf{0 . 8 0 3}$ & & & \\
PU & 0.757 & $\mathbf{0 . 8 1 8}$ & & & PU & 0.647 & $\mathbf{0 . 7 4 2}$ & & \\
OA & 0.520 & 0.764 & $\mathbf{0 . 8 9 0}$ & & OA & 0.645 & 0.684 & $\mathbf{0 . 8 2 3}$ & \\
AU & 0.254 & 0.395 & 0.335 & $\mathbf{0 . 9 1 8}$ & AU & 0.423 & 0.338 & 0.381 & $\mathbf{0 . 7 9 9}$ \\
\hline Notes: & & & & & & & &
\end{tabular}

PEOU = Perceived Ease of Use; PU = Perceived Usefulness; OA = Overall Attitude ; AU = Actual Use 